\title{
Mathematics is Ontology? A Critique of Badiou's Ontological Framing of Set Theory
}

The subject of this article is Alain Badiou's well-known assertion that "mathematics is ontology" (henceforth: $M=O$ ), a phrase that originates in the opening chapters of Being and Event, and which has been an essential orientational maxim for followers of Badiou ever since. ${ }^{1}$ In this article, I pose two questions: a) How important is the identification of mathematics and ontology for Badiou's larger philosophical project in Being and Event? And: b) Does Badiou give convincing reasons for accepting it? My answers, upon careful deliberation, are a) crucial, and b) no. The key to my counterargument is the idea that set-theoretic multiples (collections) should not be conflated with the types of 'multiples' (i.e. parts and wholes, atoms and totalities) that are traditionally within the purview of ontology. In what follows, I aim to complicate Badiou's idea that the ontological theme should be moved to the realm of set theory. ${ }^{2}$

To understand the importance of $M=O$ for an otherwise vast philosophical text, we must recall the design of Being and Event. Its basic chapter structure follows that of a typical introduction to axiomatic set theory (supplemented by extensive philosophical commentary). The scope of such an introduction to set theory includes the following subjects:

- a motivation and explanation of the axioms of Zermelo-Fraenkel set theory (ZFC) vis-à-vis the naïve concept of set/collection;

1 Alain Badiou, Being and Event, trans. Oliver Feltham, Continuum Books, London and New York 2005, pp. 4, 15, 19. The role of "mathematics is ontology" for the second and third volume of the Being and Event trilogy is a more complex matter. It is clear that the later volumes build on the first. In this paper, I only consider the argument as it is presented in the first volume, the original Being and Event.

2 However, I do not claim that set theory cannot be used as a conceptual tool in the investigation of ontological matters. In fact, it is widely presupposed as a background theory for ontological investigations that use formal logical theories as languages which 'capture' ontological reasoning and commitments. However, I take issue with Badiou's much stronger claim that set theory is the science of being qua being. 
- the development of several mathematical concepts in the language of sets functions, power sets, ordinal numbers, cardinal numbers, infinite sets, etc.;

- a presentation of the independence of the continuum hypothesis from the axioms of ZFC (a joint proof of Kurt Gödel and Paul Cohen).

However, the philosophical prestige of Being and Event does not come from its mathematical content. There are no new mathematical theorems in the book. Its status as an important work of philosophy comes from the fact that Badiou purports to extract a series of non-trivial ontological insights from the edifice of the mathematical theory of sets. Here, ontology is a field associated with philosophers such as Plato, Spinoza, Hegel, Heidegger, and Deleuze. Badiou often invokes set-theoretic results to criticise the views of these thinkers. The intensity with which Badiou reads these two traditions together is more or less unique to him. ${ }^{3}$ As a sceptical reader, I have significant doubts that they communicate to this degree without lapsing into a somewhat loose exercise in analogy-making.

It is critical to see that, prima facie, the mathematical theory of sets and philosophical ontology are two only minimally overlapping fields of inquiry, organised around quite different questions. I will return to this matter below. The formula "mathematics is ontology" is what enables Badiou's ontological hermeneutics of set-theoretic results. ${ }^{4}$ If the two fields have nothing to do with each other, it will be futile to try to critique some ontological views of, for example, Spinoza using set theory. But if he can convince us of $M=O$, then set-theoretic results can indeed be read vis-à-vis the ontological tradition, although, needless to say, different interpretations of the mathematical theorems may ensue. If the identification (or conflation) of the two disciplines is ill-founded, then his exegeses of set-theoretic findings must remain at the level of creative metaphor

3 Perhaps the way Riemannian geometry informs the work of Deleuze and Guattari is somewhat analogous.

4 Although Badiou's project is not nominally associated with philosophical hermeneutics, I submit that in Being and Event he is primarily concerned with a philosophical interpretation of set-theoretic results. (He speaks at length about his "philosophical interpretations" of set theory in the introduction: ibid., p. 19 ff.) This leads me to describe his philosophical practice as importantly hermeneutic (interpretive) in nature. By describing his project as an ontological hermeneutics of set theory, I also wish to foreground that his interpretive strategy is highly idiosyncratic in its preoccupation with ontology. It is also exactly this hermeneutic strategy that I wish to contest here. 
and analogy. ${ }^{5}$ This would not undermine his work entirely, but it would change its entire argumentative framing (and the strategies necessary in our reception of his work).

Apart from the exposition of set-theoretic concepts and theorems, Being and Event contains many pages of philosophical commentary. One can usefully distinguish between two main functions of these passages. The first is to convince the reader of the identification of set theory with ontology (the argument for $M=O$ ). The second is to develop an ontological interpretation of the set-theoretic results (an ontological reading of set theory). The latter, more voluminous task, depends on the successful completion of the former. This serves to remind us what is at stake in evaluating Badiou's identification of mathematics and ontology.

To see how resolute Badiou is about $M=O$, we turn to a telling passage from Being and Event. Here, Badiou goes beyond the set theorist Paul Cohen's account of his discovery and identifies the mathematical concept of an indiscernible part of a multiple (Cohen calls this a generic extension) with the ontological (or philosophical) concept of a truth. ${ }^{6}$ Let us see how he frames the relationship between the mathematical results and the ontological discussion:

It is mathematics which must judge whether it makes any sense to speak of an indiscernible part of any multiple. [...] it can decide whether it is compatible with ontology that there be truths. Decided at the level of fact by the entire history of humankind - because there are truths - the question of the being of truth has only been resolved at a de jure level quite recently (in 1963, Cohen's discovery); without, moreover, the mathematicians - absorbed as they are by the forgetting

5 Indeed, I take Badiou's mathematical passages as extended analogies that help the reader to understand his philosophical points. That said, I also take metaphors and analogies to be indispensable to philosophy (and to human thought more generally) and certainly do not wish to suggest that the use of metaphors discredits a thinker. However, Badiou himself seems to understand his own method as quite distant from analogy. I consider this a misrepresentation of the philosophical work that he does and especially of the justificatory structures that underly his main philosophical claims. This makes it hard to engage with him as a theoretical thinker. I am at present working on a book that is concerned with the role of analogy and metaphor in philosophical conceptual labour.

6 Paul Cohen, Set Theory and the Continuum Hypothesis, Dover Publications, Mineola 2008. For Cohen's own account of his discovery, see Paul Cohen, “The Discovery of Forcing”, Rocky Mountain Journal of Mathematics 32 (4/2002), pp. 1071-1100. 
of the destiny of their discipline due to the technical necessity of its deployment knowing how to name what was happening there (a point where the philosophical help I was speaking of comes into play). ${ }^{7}$

The relationship between mathematics and philosophy, as Badiou sees it, is the following: mathematicians come up with formal innovations that they do not fully interpret. The philosopher is then able to give the right ontological framing to the matter - "the philosophical help.” For Badiou, Cohen's proof from 1963 resolves a more profound ontological question, without Cohen being aware of it. This has been Badiou's line ever since Being and Event, although a similar motif already runs through Theory of the Subject. ${ }^{8}$ What are the philosophical underpinnings for this interpretive practice? Is his conflation of set theory with ontology justified?

Favourable commentators have accepted Badiou's identification of mathematics and ontology, often without even recognising its prima facie implausibility. ${ }^{9}$ One might explain this by noting that in contemporary philosophy 'ontology' describes a whole array of only loosely related approaches and questions. ${ }^{10}$ It is not my goal to propose an alternative vision of ontology here, only to cast doubt on Badiou's identification of mathematics (set theory) with ontology.

In comparison with his commentators, Badiou seems quite aware of the implausibility of his identification of ontology and mathematics. He fully accepts that he must deliver a "proof that mathematics is ontology."1 But although Badiou claims to give such a proof in Being and Event, it is not very clear which

8 Alain Badiou, Theory of the Subject, trans. Bruno Bosteels, Continuum Books, London and New York 2009, pp. 148-157.

9 See, for example, Steven Corcoran (ed.), The Badiou Dictionary, Edinburgh University Press, Edinburgh 2015; A.J. Bartlett and Justin Clemens (eds.), Alain Badiou: Key Concepts, Acumen Publishing Limited, Durham 2010; Burhanuddin Baki, Badiou's Being and Event and the Mathematics of Set Theory, Bloomsbury Academic, London and New York 2015. Since Being and Event is built entirely on the proposition that mathematics and ontology can be identified, any interaction with Badiou's (systematic and philosophical) work almost presupposes acceptance of it.

${ }_{10}$ The field is hard to circumscribe, 'ontology' seems to mean something different for most authors, some believe that it does not constitute an actual field of inquiry, etc.

${ }_{11}$ Badiou, Being and Event, p. 19. 
parts of the book pursue this goal. For instance, there is no passage in which he indicates to the reader that he considers the proof complete (presumably it is concluded by the end of Part I). Neither does he pause to state any kind of adequacy criteria therefor - what would make for a successful proof of his equation? Against the mathematical background of much of the material discussed in Being and Event, Badiou's notion of a philosophical proof (for $M=O$ ) is remarkably implicit. So, if one wishes to evaluate the central philosophical claims of Being and Event charitably (especially concerning its mathematical content), one cannot get around formulating adequacy criteria for the identification of mathematics and ontology oneself. What kind of argument would settle this matter to our satisfaction?

Theoretical discourses with different statuses flank both sides of the identity $M=O$. Badiou's reading of the history of philosophy is that the ontological tradition failed to fulfil its theoretical desiderata. However, mathematics (here in the guise of modern set theory) satisfies these desiderata without knowing it. ${ }^{12}$ So the identification relies on a) establishing that ontology in all its historical variance ultimately circles around a handful of central theoretical themes and challenges, and on b) showing that ZFC manages to address (resolve?) these themes and puzzles in a more apt way than the classical philosophical programmes did. This description of what Badiou has to show is still sketchy, but it is fair to the spirit of Being and Event. ${ }^{13}$ To summarise: to be successful, an argument in favour of $M=O$ would have to achieve three things:

a) describe the themes and desiderata of ontology anew;

b) describe the theme and achievements of set theory anew;

c) check that these desiderata and achievements match.

I believe that Badiou fails to make a convincing case for $M=O$ on account of his implausible descriptions of both ontology and set theory. The impression that these two discourses align is a consequence of his tendentious characterisation of both.

${ }_{12}$ Ibid., pp. 9-11.

13 See, for example, the meditation on Spinoza, ibid., pp. 112-21. 
Let us zoom in on a) and b). Badiou's argument is that ontology (qua collective philosophical endeavour) has arrived at a point where ontology recognises the need for a theory of the multiple (a term that I aim to problematise in what follows), but has failed to supply anything theoretically respectable. ${ }^{14}$ Set theorists, on the other hand, have managed, he alleges, to create precisely such a theory - a theory of the pure multiple - without fully realising the ontological implications of their creation. As critical readers, all we have to do is check that the word "multiple" means the same thing on both sides of the equation $M=O$, since Badiou's principal contention is that despite the tunnel vision of mathematicians, their work speaks to the ontological theme directly. ${ }^{15}$ I object that there is too much semantic slippage between the two uses of 'multiple' (first referring to the ontological multiple, then referring to the sets from set theory) to accept Badiou's identification. This issue wreaks havoc on Badiou's philosophical project in Being and Event (but not on set theory as an independent mathematical discipline, of course). In what follows, I will go back and forth between ontology and mathematics in order to spell out how the signifier "multiple" takes on a quite different meaning on both sides.

There are two types of problems on the side of ontology. The first is that the ontological word 'multiple' indeed means something different than in mathematics (the mismatch problem). The second problem is that Badiou's call to put a figure of the multiple (as opposed to a figure of the one) at the centre of ontology appears ad hoc, despite Badiou's efforts to imbue the idea with a mood of epochal necessity (the motivation problem). ${ }^{16}$

14 It is not entirely clear who is taken to hold this view. The mood is one of diagnosing epochal philosophical tendencies.

15 In fact, Badiou holds the view that set theory is so fruitful ontologically that all first-order ontological theorising is done by set theorists in the first place. Philosophy's function is second-order commentary. Ibid., pp. 1-22.

16 An alternative explanation is of course that Badiou started with some analogical interpretations of set-theoretic results, only to find a fitting philosophical rubric - ontology and afterwards to package them so as to appear more attractive to the philosophical readership. This view is corroborated by the fact that Theory of the Subject (a book written before Being and Event) already contains an interpretation of Gödel's and Cohen's results. However, in the earlier book there is no mention of a systematic ontological role for set theory as a new theory of the pure multiple. Here, Badiou appears content to present his approach to mathematical thought as being more hermeneutical in character. Badiou, Theory of the Subject, p. 148. 
To evaluate Badiou's proof, we have to look at his descriptions of the ontological problematic against the backdrop of what we know about set theory and vice versa. In other words, we should study his characterisations of ontological impasses and then ask ourselves whether mathematical set theory offers a sound solution.

The shift that Badiou wants to effect is the following. Without $M=O$, the relevance of Gödel's and Cohen's work on the independence of the continuum hypothesis is completely intra-mathematical (the local relevance of Gödel-Cohen). If set theory is somehow concerned with "being qua being," a term coined by Aristotle, on the other hand, this will make their results more universally relevant - given some philosophical guidance (the global 'philosophical' relevance of Gödel-Cohen). This is the work that the identification of mathematics (set theory) and ontology does for Badiou's philosophical project in Being and Event. ${ }^{17}$

It is quite natural to question the claim of the global relevance of set theory to themes from classical philosophical ontology. Modern set theory arose as a response to the increasing use of an intuitive (naïve) concept of collection/set in mathematics (sets of objects, sets of numbers, sets of functions, extensions of concepts, etc.). This led mathematicians to investigate infinite sets and the discovery of a framework for distinguishing different sizes of infinite sets (Cantor). Of course, classical ontological thinkers had also concerned themselves with infinity, insofar as they tried to elucidate the foundational concepts of mathematics (e.g. Hegel's Science of Logic, the section on Quantity)..$^{18}$ But at the foreground

${ }_{17}$ See Badiou's remark that Cohen's results should become an "intellectual topos at least as famous as Godel's [sic] famous theorems [...]. They resonate well beyond their technical validity.” Badiou, Being and Event, p. 16.

18 Georg Wilhelm Friedrich Hegel, The Science of Logic, trans. George di Giovanni, Cambridge University Press, Cambridge 2010. With regard to infinity, one should probably separate two aspects. The first concerns the elucidation of different concepts of infinity. In this regard, Cantor and the set theorists are of course important for showing that a certain conceptualisation of infinity (in the context of sets/collections) leads us to accept a typology of different types or sizes of infinity - a typology that is of considerable mathematical complexity and utility. But this conceptual innovation should not be conflated with metaphysical or ontological questions that are concerned with the finite or infinite nature of the universe or of any fragment of reality, let alone of being qua being. This second aspect presupposes some concept of infinity and then asks regarding certain entities whether they are finite or infinite. The cultivation of concepts of infinity and the investigation of the 'size' of certain ontologically relevant entities are two separate but related intellectual 
of classical ontology is the elucidation of the concepts of being, entity, object, nature, substance, quality, necessity and possibility, space and time, concept, matter, subject, agency, etc. - concepts that seem presupposed in most, if not all, of our conceptual dealings and behaviours, regardless of the precise matter at hand. ${ }^{19}$ Insofar as mathematics sometimes develops formal counterparts of these concepts (classically: space and quantity), it offers tools for answering questions posed by philosophers. However, it is of utmost importance to differentiate Badiou's approach from the more typical mingling of philosophy and mathematics. What makes his approach unique is that he approaches the concept of being itself via the notion of multiple, which he then identifies with the mathematical notion of set.

Returning to set theory, one should keep in mind that the naïve concept of set is grounded in our basic experience with collections of objects that are not collections themselves. For example, we might consider the collection of chairs in room 101 - a collection that contains basic objects of our everyday experience. It is only after a second step that mathematicians after Cantor started to focus on collections of abstract objects (numbers) and on collections of collections (subsets of the set of natural numbers), which led to the development of a formal set theory that does not involve any non-set objects. The most well-known example of such a theory is ZFC. In any case, it is not at all obvious how the concept of set/collection (in whatever stage of formalisation) can be used to elucidate any classical ontological category not directly concerned with quantity or extension, such as the concepts of object, being, or substance. We can use set-theoretic tools to model metaphysical categories. Still, we should not identify the domain of discourse of ZFC with the realm of being qua being (without an intricate argument).

In contrast, the widely held (and, in my opinion, correct) view is that formal set theories are axiomatisations of the naïve concept of collection - nothing more

enterprises. It is certainly possible to wholly affirm the conceptual innovations of the set theorists without also having to submit to the much more contentious view that being qua being (or any other metaphysical or physical category!) is infinite.

19 The preference for the label 'ontology' over the label 'metaphysics' here merely shows the prioritisation of the concept of being in the wider investigation. Also, needless to say, classical ontology also often goes hand in hand with theological themes (onto-theology), something which I have not emphasised in my discussion here. 
and nothing less (the common sense scope of set theory). ${ }^{20}$ Whenever we are concerned with talk of collections, extension, and cardinality, set theory can become relevant. But it is certainly not prima facie evident that the very concept of collection is of foundational significance to classical ontology. But this is precisely Badiou's central claim in Being and Event when he declares that mathematics is ontology. How does his argument work?

It seems to me that, in Badiou's view, the central notion of ontology is the notion of any being whatsoever. (Other notions that could play a role are those of object and entity, although Badiou avoids these terms. He often uses the Aristotelian phrase "being qua being".) I take it that the task of ontology is to characterise being qua being adequately. Now, one can undoubtedly pause here to ask whether this even constitutes a sufficiently clearly circumscribed theoretical field - a certain scepticism about this project is widespread even among philosophers, myself included. But Badiou is not agnostic on these matters; he brings a surprising and strong desideratum into play at this level: being qua being must not be one (this is captured by the slogan "the one is not"). ${ }^{21}$ There are two conceptual ingredients to this desideratum. First of all, the concept of parthood (pure being must have several parts, components, constituents, etc.). Second, the ban on unity (pure being must have several parts, pure being is not to be approached through the theme of unity). But as I will show, we should be careful to not conflate different types of part-whole relations here.

20 The naïve concept of collection has several origins. On the one hand, instead of considering the objects on the table individually, we can reify this into the set of objects on the table. This spontaneous talk of collections of objects (however concrete or abstract) is one source of intuition regarding the concept of collections. Another, related, background aspect is the notion of an extension of a concept (Frege). The extension of the concept 'dog' is not a spatio-temporal object but a collection of dogs. But neither of these are in an obvious way related to the ontological category of being qua being. Rather, they are related to everyday talk of quantities and extensions. Presumably, our competence with the notion of set/collection builds on our familiarity with the embodied practice of putting several objects inside of a container, allowing us to treat them as one object whilst also retaining the distinctness of the objects inside of the container. The mathematical concept of set is an abstraction of this embodied concept. See George Lakoff and Rafael E. Núñez, Where Mathematics Comes From: How the Embodied Mind Brings Mathematics into Being, Basic Books, New York 2000, pp. 140-54.

${ }^{21}$ Badiou, Being and Event, p. 23. 
My challenge to Badiou is that this desideratum is poorly motivated philosophically (arbitrariness) and that it does not get us to set theory on the side of mathematics (poor fit). I will work backward here and start by explaining why "the one is not" may seem to pave the way to a set-theoretic ontology, only to problematise this trajectory afterward. In the second step, I will question whether there is an intrinsic ontological motivation for "barring oneness from being" at all.

According to Badiou, being must be devoid of all oneness. The practical consequence of this claim is that if we can find a theory describing (formalising) entities that are multiple but not one, we may proceed to treat it as our new ontology, and hence, as a theory with broad philosophical consequences. Here is a key fact about ZFC which contributes to the impression that it is a "theory of the pure multiple": (ZFC has no 'atoms' or urelements). ${ }^{22}$ The entities of ZFC are pure sets. That is, there are only sets of sets, but no primitive entities that are not sets. ${ }^{23}$ Hence, the entities of ZFC are 'multiples' composed of further 'multiples'. They do not decompose to an atomic base-level of non-set objects.

Let us summarise. On the side of ontology, Badiou identified a demand for a theory of being without oneness; on the side of mathematics, he came across a formal logical theory of multiples that appear not to reduce to atoms (multiples without 'the one'). It seems like a perfect fit. But there are two open questions:

1) it is unclear what exactly motivates the ontological desire for a multiple without the one;

${ }_{22}$ Terminologically, 'urelements' is really more accurate here than 'atoms'. Even in set theories that do admit urelements, the relation between sets and urelements is not the one between a spatio-temporal object and its smallest constituent parts. Any talk of atoms in the context of set theory is metaphorical, which is why the more technical terminology of 'urelements' is preferable.

23 Badiou seems to make much of the fact that formal set theories (ZFC and its extensions) talk of sets only, without needing to refer to non-set objects. If we take a theory such as ZFC in isolation, it seems to commit us only to a universe of sets, and nothing else. However, this is simply a side effect of the fact that in formal logical theories we consider certain conceptual systems in isolation. Another formal theory, such as Peano Arithmetic (PA), considers the system of natural numbers in isolation. But neither ZFC nor PA should lead us to the idea that "there are only numbers" or that "there are only multiples." Badiou, Being and Event, p. 61. 
2) we also have not sufficiently explored whether or not sets are the type of multiples that can play the role of Badiou's ontological 'multiple without the one'. What kind of multiples are sets exactly?

It is undoubtedly true that the objects of ZFC, developed out of the need for a more rigorous concept of collection than the quotidian (naïve) one, can be characterised as 'multiples'. The word 'multiple' itself suggests little more than that the object in question is composed of many. Indeed, most sets have many elements. If they have exactly one element, that element is a set itself, so one level deeper it decomposes into many elements. Some synonyms for 'set' are 'aggregate', 'collection', 'Menge', and 'ensemble'. These all emphasise the aspect of plurality and de-emphasise the aspect of unity, that which holds the elements together. This is certainly an important part of the set concept, since nothing much is required in order to keep the elements together to yield a legitimate set. ${ }^{24}$ This stands in stark contrast to the type of unity that holds together the parts of a spatio-temporal object, for example. But is the set-theoretic notion of a collection the kind of multiple that is adequate for being qua being? Why would it be? Let us proceed by comparing and contrasting what is known about set theory with Badiou's description of the pure multiple as an ontological figure.

One important aspect of set theory, which seems quite alien to ontology as a theory of being qua being, is the following: sets (or 'collections') have a distinctly combinatorial flavour. In short, the idea is that any combination of elements whatsoever that does not lead to paradoxical situations should yield a legitimate set. A simple example helps to demonstrate the combinatorial wealth of set theory. The set $X:=\{5,\{1,2,5\},\{\{5\}\}\}$ has three elements: $5,\{1,2,5\}$, and $\{\{5\}\}$. Here, the number 5 occurs three times, on several levels: once as an element of $X$, once as an element of an element of $X$, and once as an element of an element of an element of $X$. Since these are all viably different combinations, $X$ is a legitimate set. Also, notice that 2 is not an element of $X$, even though it is an element of an element of $X$. It is no exaggeration to claim that set theory was created to encompass these types of embedded ('nested') membership systems. But this does not seem to be a feature of being qua being on any available interpretation of the term. It seems to be a unique and defining feature of sets, which differentiates them from pretty much any other type of entity.

24 Except for the care needed to prevent paradoxical sets. 
Another formalism needs to be introduced here: mereology. Whereas modern logicians and mathematicians developed set theory to axiomatise the notion of collection, they also developed the theory known as mereology to axiomatise the part-whole relationship. Oddly, mereology is never mentioned by Badiou. Introducing mereology prepares the second step of my argument, in which I aim to show that Badiou's reading of classical ontological arguments suggests a mereological, not a set-theoretic interpretation. My point will be that in his reading of philosophical authors such as Lucretius and Plato, Badiou problematically conflates these quite distinct concepts into a single concept of 'multiple', which seems to be a mixture of the two. To a large degree, the identification of ontology with set theory can only arise due to the conflation of the collection concept (set theory) with the part-whole relation (mereology).

We can familiarise ourselves with the mereological notion of parthood by taking a Volkswagen Golf and its parts as an example. ${ }^{25}$ The steering wheel is a part of the car. The car is a whole comprised of such parts (a 'multiple'?). The relationship between a mereological whole and its parts should be kept distinct from the relation between a set and its elements. To see that they are different relations, consider the mereological example of the driver's seat and its headrest. The headrest is part of the seat, and the seat is part of the car. By virtue of this, the headrest is a part of the car as well. This parthood relation is transitive. ${ }^{26}$ Axiomatisations of the mereological parthood relation usually include transitivity either as an axiom or as a direct consequence of other axioms. Comparing this to the set-theoretic axiomatisation of membership $(\in)$, we note that the elementhood relation is not transitive. To see an example of this, consider a flutist named Allen, who is a member of a marching band (viewed as a collection of musicians). The marching band itself is a member of the set of active musical groups in France. But Allen himself is not a member of the set of musical groups. Set-theoretic elementhood is intransitive. Sets and mereological wholes are different types of multiples. ${ }^{27}$ There are several other essential dissimilarities between the two notions, which is why they yield different axiomatisations.

${ }_{25}$ For a more extensive introduction, see Achille Varzi, “Mereology”, Edward N. Zalta (ed.), Stanford Encyclopedia of Philosophy, 2016, https://plato.stanford.edu/archives/win2016/ entries/mereology/.

26 A relation $R$ is transitive if: $\forall a \forall b \forall c(R a b \wedge R b c \rightarrow R a c)$.

${ }_{27}$ That said, a subset of a set is like a mereological part of a set. (Sets have parts analogous to how mereological wholes have parts.) However, this should not allow us to infer the 
To summarise: mereological axioms, not set-theoretic ones, formalise the material parthood relation. Soon, we will see that the thinkers that Badiou discusses (aiming to establish the necessity of a set-theoretic ontology) use what look like mereological concepts. Hence, their propositions regarding such matters are best formalised using mereology.

It should be pointed out that as a family of formal theories, mereology does not come with such surprising results as the independence of the continuum hypothesis. Unlike set theory, mereology is not replete with paradoxical niceties that might invite philosophical interpretation. My suggestion here is not to replace Badiou's set-theoretic ontology with a mereological one with similar ambitions (and then to offer philosophical interpretations of meta-theorems about the mereological theories). Instead, my point is simply that the parthood vocabulary used in certain philosophical discussions (and as we will see, in Badiou's treatment of ancient sources such as Lucretius and Plato) is best formalised using mereological theories. ${ }^{28}$ Set theories are simply not what is called for when formalising these ideas since they do not concern the extension of sets, but the parthood structure of mereological objects. As we will see, Badiou seems unaware of this.

Now that we have introduced the distinction between collection-multiples and mereology-multiples, we can return to Badiou's claim that a theory of the pure multiple is needed in contemporary ontology. We must now ask which flavour of formal theory fulfils his ontological desideratum. As stated earlier, Badiou's ontological demand is that being qua being is a multiple without unity. In other words, being qua being ought to be some sort of multiple whose parts are also

inverse statement: that all parthood relations reduce to set theory. This is clearly not the case even at an intuitive level, since we can employ the mereological vocabulary of parts and wholes without treating our objects as collections. For example, nothing obliges me to treat my car as a set just because I want to talk about its parts. I might be able to name many mereological parts of the car. My description may exhaust our knowledge of the car, including its subatomic particles. Set-theoretic elements are not needed on any level. Similarly, I might use a list to describe the components of the car. But this does not commit me to the view that the car itself is list-structured. There is a difference between what is cognitively salient and what is ontologically real.

28 There is considerable literature that applies modern mereological thought to reconstruct ancient doctrines. One example is: Verity Harte, Plato on Parts and Wholes: The Metaphysics of Structure, Clarendon Press, Oxford 2002. 
multiple. We have already seen why Badiou believes that this description fits the set-theoretic framework. However, let us study some of the passages in which he describes what conceptual innovations are needed in ontology, passages where he engages in a reading of classical ontological texts. We will see that a mereological concept of part-whole is more suited.

On several occasions Badiou presents his ontology of the pure multiple as a modern realisation of the ontological programmes of ancient thinkers such as Parmenides, Plato, and Lucretius. In a companion essay to Being and Event, entitled The Question of Being Today, Badiou quotes the following lines from Lucretius' On the Nature of Things:

Such is the nature of the place, of the gigantic space:

Were it to slide, forever drawn away by time,

Lightning would never see distance reduced

The whole enormous reservoir of things is open

In all directions. ${ }^{29}$

He describes Lucretius as "the one who directly confronts thought to subtraction from the One, which is none other than inconsistent infinity, that is, what nothing can collect." ${ }^{30}$ This requires some critical commentary. First of all, let me repeat that Badiou's goal in this passage is to establish that ontology requires a theory of the multiple without oneness (i.e. set theory). Presumably, he cites Lucretius as an early adherent of (a pre-modern anticipation of) such a doctrine. We must ask two questions here: a) What kind of multiple is Lucretius describing? b) What role does the subtraction of the one play for Lucretius?

Turning to the first question: it is quite clear, despite the brevity of the passage, that Lucretius is describing the nature of a spatial whole ("the whole enormous reservoir of things") - something like the universe or the cosmos. His main claim here seems to be that it is infinite in size ("open in all directions"). However, such a spatial structure should not be mistaken for a set! A spatial whole

29 This is a translation of Lucretius, De Rerum Natura, 1.1002-8. Cited in Alain Badiou, "The Question of Being Today", in Briefings on Existence: A Short Treatise on Transitory Ontology, trans. Norman Madarasz, SUNY Press, New York 2006, p. 35. Madarasz bases his translation on "the French version used by Badiou." Footnote 6, p. 174.

30 Ibid. 
has (mereological) parts, not set elements. So, if one were to capture Lucretius' theorising up to this point in some kind of formal logical system, it would be a mereological (or mereo-topological) theory, not a set-theoretic one. Set-theoretic vocabulary may of course come in when we need to discuss how many parts (extension!) a spatial whole has. But in that function it serves to formulate quantitative (or extensional) statements about objects which are themselves not sets, but spatial wholes. So this would lead us away from Badiou's idea that set theory speaks directly to the ontological category of being qua being.

With regard to the second question, concerning the subtraction of the one, we have seen that Lucretius claims that there is no outside border of the universe, that it is open in all directions. This is akin to saying that the universe is not a finite ('closed') mereological whole (or unity). Paraphrasing, one could claim that the universe is not 'one' in the sense that a finite object is one (if we identify unity with boundedness). So, on this route we may indeed come to the conclusion that Lucretius "confronts thought to subtraction from the One," as Badiou writes, although it remains a tendentious formulation. Most importantly, Lucretius' description is indicative of a mereological vocabulary (parts, wholes, boundaries), not a set-theoretic one. He considers the universe from the perspective of its mereological structure. It is not clear how to paraphrase Lucretius' specific view in the language of sets, since it is about a spatial whole, not a set. Instead, we should probably read him as claiming that the universe is unlike any cognitively more familiar region of space, insofar as it is unbounded. ${ }^{31}$ His claim is primarily preoccupied with the existence of outer boundaries, and not with questions of extension or numerosity. Although this is certainly a revolutionary position by the standards of Lucretius' contemporaries, it remains opaque how he can be cited in favour of a connection between being qua being and set theory.

Here, I would like to make a final remark as regards understanding Lucretius from a contemporary perspective. As stated, his main concern in the cited passage seems to have been the boundlessness of the physical universe. Spatial

31 This is not to say that mereological or mereo-topological statements cannot be modelled in a set-theoretic context. The point is that the specific "subtraction of the one" that Badiou finds in Lucretius concerns a very specific claim about the boundedness of the universe, which simply does not contribute anything to the much more outlandish claim that the ZFC axioms codify something about being qua being. 
boundlessness is a variation on the theme of infinity, but not quite the same as the extensional infinity of sets. Since the idea of actually infinite extensions was unknown to the Greeks, we cannot expect Lucretius to have also explored the correlative idea that an unbounded universe (spatial infinite) may have infinitely many (extensional infinite) parts. However, from a modern point of view, this question comes naturally. How many parts does this unbounded universe have? This type of question mixes mereological and set-theoretic vocabulary. We are now considering the cardinality of a set of parts of a material whole. This is a totally natural situation, which motivates the presence of set-theoretic vocabulary. But notice that this is a set of non-set entities (the parts of space). So, it does not suggest that being qua being is set-theoretically legible. Rather, it merely suggests that when considering questions of cardinality (and combinatorics), set theory is a natural conceptual tool.

Very similar criticisms apply to Badiou's take on Plato's Parmenides in meditation two of Being and Event. Here he focuses on unity not at the largest level, but at the smallest, atomic level. Badiou goes on to conclude that ZFC set theory, which has no urelements, is a description of the kind of multiple without the one that Plato considers, but fails to elaborate, in the Parmenides. Let us take a look at the passage from Parmenides to see whether the key propositions have a set-theoretic or a mereological character.

One of the questions that Plato investigates in the Parmenides is whether we can describe being if we drop the characteristic of unity - the hypothesis "if the one is not." ${ }^{32}$ For Plato (or at least for the dramatis personae of the Parmenides), the result is deeply aporetic. The interlocutors in the Parmenides abandon the option that being without unity can be thought at all. But for Badiou, in contrast, the way the aporia is spelled out by Plato unwittingly indicates a new way forward, which he labels "the multiple without the one." Although Plato did not see a way to theorise being without the one consistently, Badiou believes that modern set theory delivers precisely such a theory. Here is the passage from the Parmenides that Badiou believes indicates a set-theoretic opportunity:

If one took the point of being which seemed to be the smallest, much like a dream within sleep, it would immediately appear multiple instead of its semblance of

32 Plato, Parmenides, 16ob-166c, as quoted in Badiou, Being and Event, p. 31. 
one, and instead of its extreme smallness, it would appear enormous, compared to the dissemination that it is starting from itself. ${ }^{33}$

This line of thought is an outlandish consequence of the hypothesis of being without the one. More specifically, the idea seems to be that if there are no smallest parts, then every part must contain more parts, ad infinitum. Another way to phrase this is that if there is no fundamental unity to being, then there is no level at which one will encounter undecomposable atoms. The image is one of infinite zoom levels - at each level there are more parts to discover.

This view may be hard to fathom for Plato's interlocutors (and possibly for Plato himself) because they tacitly subscribe to an atomistic picture of spatio-temporal objects. Without there being smallest units, there is nothing the bigger composites can be composites of. So they reject this position as aporetic. ${ }^{34}$

We should now keep two concerns separate. First of all, it is essential, once more, to firmly establish that the type of parthood relation that occurs in the cited passage is mereological. We take some fragment of being (we quite literally 'take' some chunk of reality and examine it), then try to find its smallest part, only to discover that it has many parts all over again. This type of language, used in the passage cited above, is indicative of spatial mereological wholes and parts, not of sets, since only spatial wholes have smaller parts..$^{35}$ By way of contrast, there is no guarantee that an element of a set is 'smaller' than the set itself (if we understand 'smaller' in the sense of cardinality - but that is the only notion of size available for sets). Although any interpretation of Plato's Parmenides

33 Plato, Parmenides, 164d, as quoted in Badiou, Being and Event, p. 34. Parmenides addressing Aristotle.

34 A similar sentiment is found in Leibniz, in one of his letters to Arnauld: "I maintain that there is no better way to put philosophy back on its feet and turn it into something precise than by focusing on individual substances or complete entities that have genuine unity, their changes all being caused from within themselves; everything else is mere phenomena, abstractions or relationships. We'll never find any rule or recipe for making a genuine substance out of many entities by aggregation.” Gottfried Wilhelm Leibniz and Antoine Arnauld, The Correspondence between Leibniz and Arnauld, trans. Jonathan Bennett, 2017, https://www.earlymoderntexts.com/assets/pdfs/leibniz1686a_1.pdf, p. 62.

35 In fact, the Greek word root $\mu \dot{\varepsilon} \rho$ - (part) occurs over 50 times in the discussion between Parmenides and Aristotle, concerning the different hypotheses about being and the one. 'Mereology' takes its name from this Greek root. 
is bound to be contentious - I certainly do not aim to develop my own here - my goal has been merely to point out that more work is needed to cast the central propositions in set-theoretic terms.

It is undoubtedly true that Plato's interlocutors (Parmenides and Aristotle) consider the idea of an atomless reality hard to swallow. However, modern mereology teaches us that we can introduce an axiom that states that all objects are atomless into a mereological theory without running into any mathematical inconsistencies:

The axiom of atomlessness: Every object has at least one proper part.

If an atom is an object without proper parts, then this axiom bars the existence of atoms..$^{36} \mathrm{~A}$ mereological theory that includes this axiom would perhaps be a 'theory of the pure multiple without the one' in the spirit of the above passage of the Parmenides. From a contemporary mathematical perspective, such theories are known to be consistent. ${ }^{37}$ However, since this question concerns the makeup of our physical universe, one would have to leave the final word to physicists. But modern atomic physics has long surpassed any sort of simple mereological approach to atoms, shifting its focus instead to the forces at work in keeping matter together. And even if quarks are the smallest (indivisible) particles, it still does not mean that physical objects are sets (unstructured collections) of quarks. Instead, they are some sort of structured constellations of them. The structure of such constellation is what modern physics aims to understand. The mereological aspect plays little to no role.

To summarise, if one wanted to pick up the argument where the interlocutors of Plato's Parmenides leave it, one would do so with mereological ideas (supplemented by physical theories), not set-theoretic ones. (Set-theoretic cardinality concerns can come in later, but do not imply that the entity in question, a spatial fragment of reality, is a set.) So, it is quite unclear how any reading of the Parmenides can lend support to the proposal that set theory is a privileged site

${ }_{36}$ 'Atom' is here used in the sense of 'smallest indivisible part', not in the sense of contemporary physics, where atoms have smaller constituents.

37 The open sets of a Euclidean space are a model of an atomless mereology. See Varzi, "Mereology". 
of ontological speculation. More specifically, the proposition of excluding unity at the microscopic level of being (the idea explored in the Parmenides) is not at all captured by ZFC set theory, which is not a medium for theorising about the part-whole structure of being at all, but a theory of collections. ZFC, as a theory of sets of sets, has no real purchase on the entities discussed by the ancients.

The above objection is more or less independent of the role that unity plays in Badiou's argument. As I have indicated, the propositions a) that there is no universal whole (Lucretius) and b) that there are no atoms (Plato's thought experiment in Parmenides) are stated in mereological vocabulary. The broader class of mereological theories includes theories that affirm or deny these theses. So, at the outset, mereology (the study of a class of formal theories that isolates the part-whole relation) is neutral with regard to these propositions, and can hence serve as a vehicle for further investigation.

Now, regarding the matter of the barring of the motif of unity from ontology: my position is that there is no strong philosophical reason for assuming that being qua being does or does not have the characteristic of unity. Also, as we have seen, Badiou's framing of the passages from Plato and Lucretius is somewhat tendentious, since he frames the specific questions of totality and atomicity as matters pertaining to the broader rubric of unicity.

Regardless of these minor framing concerns, one can also ask whether Badiou gives a substantial and independent ontological motivation to bar 'the one' from being qua being. Although unity is sometimes more projected than real, it is nonetheless a fundamental (yet not fully understood!) facet of our conceptual (and perceptual) apparatus. Although Badiou claims the opposite, modern set theory can equally be construed as an extension of our cognitive talent at unifying heterogeneous substance into a whole (in an extended sense) - set theory as a consequence of the human talent for unification. Returning to Badiou, we have already seen that when it comes to his ancient references, it is not straightforward why a contemporary ontological programme must avoid the theme of unity, since a close reading of these texts invariably leads to a discussion of issues within the purview of modern physics (atoms, the universe, etc.).

Apart from these analyses of ancient philosophical texts, Badiou gives several other reasons to push the pure multiple to the foreground of the ontological 
agenda. Some of these build on interpretations of other philosophers (e.g. Hegel, Nietzsche, Heidegger, Spinoza), and some of them have a more argumentative character. For example, meditation one of Being and Event concerns itself with establishing the necessity of postulating that being qua being must be pure multiplicity. ${ }^{38}$ However, upon closer inspection, Badiou gives no independent argument here. Rather, he introduces the maxim "the one is not" as a sort of philosophical axiom. If anything, the indirect argument is that those ontological programmes which made unity a strong characteristic of being qua being failed. However, there are reasons to doubt that Badiou demonstrates this. At best, he establishes that one may attempt the alternative. It appears to me that there is no independent framing of the theme of ontology here, one not designed with the final goal in mind of recognising set theory as a theory of the pure multiple. In subsequent parts of the book he does not dwell on whether $M=O$ has been successfully established.

Let us close this examination by looking at one of Badiou's remarks on Nietzsche. Nietzsche famously declared that God is dead. Insofar as theology sees in the monotheistic God of Christianity a figure of the one, we could interpret Nietzsche's intervention as a warning against the theme of unicity in ontology. This is what Badiou indeed does in an instructive passage of Number and Numbers, which compresses his proof of $M=O$ to the point of extreme brevity:

Modernity is defined by the fact that the One is not (Nietzsche said that 'God is dead', but for him the One of Life took the place of the deceased). So, for we moderns (or 'free spirits'), the Multiple-without-One is the last word on being qua being. Now the thought of the pure multiple, of the multiple considered in itself, without consideration of what it is the multiple of (so: without consideration of any object whatsoever), is called: 'mathematical set theory'. Therefore every major concept of this theory can be understood as a concept of modern ontology. ${ }^{39}$

We can undoubtedly embrace Nietzsche's healthy scepticism towards monotheism. But does that get us all the way to the claim that the ZFC axioms codify being qua being? It seems not. As we have seen throughout this paper, the leap

38 Badiou, Being and Event, pp. 23-30.

39 Alain Badiou, Number and Numbers, trans. Robin Mackay, Polity Press, Cambridge 2008, para. 7.16. 
is enormous. Why do we need to replace the monotheistic God (a figure of the one) with another ontological figure (the pure multiple)? Should set theory take the place of onto-theology? If God does not exist, then it would appear that no specifically theological word on being qua being needs to be spoken at all. And even if we were to accept the necessity of a replacement figure, the subtraction of oneness from being would not get us to the sets of ZFC. It would get us to atomless mereology, a position that might be of interest to some logicians, but not to someone like Badiou, who wants to bridge ontology with the theory of subjectivity.

What is most important about the cited passage, however, is the final sentence, its outcome. If the identification succeeds, then Badiou can treat the fruits of set theory ("every major concept") as direct ontological insights. This indeed seems to be the real justification of "mathematics is ontology": it serves to disguise the rather loose and analogical nature of Badiou's use of mathematics. Instead of using mathematical tools to answer questions about the nature of reality, Badiou instead interprets mathematical results directly. He presents his idiosyncratic interpretations as rigorous consequences of the work of Cantor, Gödel, Cohen, etc. The complicated intermediate steps have been compressed by way of a direct identification. This makes it exceptionally difficult to evaluate his ontology on a strictly philosophical basis, since most, if not all, of his central concepts are elaborated through complex analogies between philosophical themes and the theory of sets. Instead of giving his reader a guide to interpreting his analogies as analogies, he continues to present his work as a rigorous mathematical ontology. A philosophical project that is in truth experimental and heuristic in nature is presented as a faithful unpacking of the consequences of the innovations of others (Cantor, Gödel, etc.). ${ }^{40}$ It is this meta-philosophy itself (i.e. an informal model or picture of philosophical activity) to which I object most strongly (insofar as it opens the door to extreme forms of dogmatism).

40 This stylisation of philosophical activity through the heterogeneous field of mathematics is not entirely innocent. It has recently been characterised as a "project of the re-education of philosophy through mathematics," in François Laruelle, Anti-Badiou: On the Introduction of Maoism into Philosophy, trans. Robin Mackay, Bloomsbury Academic, London and New York 2013, p. vii. Similar complaints have been lodged in Ian Hunter, "Heideggerian Mathematics: Badiou's Being and Event as Spiritual Pedagogy”, Representations 134 (2016), pp. 116-56. Despite their observant remarks, both authors frequently lapse into caricature. 
A final remark on how I believe we should read Badiou. Despite his great love for mathematics, he is probably most known for philosophical ideas that do not fall within the purview of classical ontology. His central doctrines concerning events and truth procedures are perhaps better understood as falling within the fields of philosophical anthropology or social ontology since they are ultimately concerned with the possibility of certain types of (collective) human action. ${ }^{41}$ The central question is always what it means to be a human being situated in a socio-historical cultural field of artistic, scientific, political, and amorous innovations. Perhaps it is time we read Badiou on that level, letting go of the idea that his anthropological claims are mathematical consequences of a deeper involvement with ontology (which is how he, at least part of the time, describes his systematic endeavours in the Being and Event trilogy). What if we turned Badiou on his head and finally understood that his ontology is analogical and heuristic in nature, yet ultimately indexed to his avant-garde anthropology, and not the other way around?

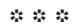

\section{Postscript}

At the 2018 conference in Prague where I presented a shorter and less critical version of this paper, Badiou gave a response paper (addressed to all the contributors) in which he explicitly addressed the role of his formula "mathematics is ontology." An edited version of this response is included in this volume. ${ }^{42}$ Since his talk was rather surprising, I would like to end with a brief response.

In his talk, Badiou admitted ("confessed") that the formula $M=O$ is only "a sort of mediatic formula," or "a propagandist formula" which is "condemned to a terrible failure." ${ }^{43}$ He furthermore claimed that he brought ZFC set theory into ontology because he saw a new tool to continue the ontological orientation of

${ }^{41}$ Badiou occasionally describes his work as having an anthropological scope. See Alain Badiou, "Affirmative Dialectics: From Logic to Anthropology", The International Journal of Badiou Studies 2 (1/2013), pp. 1-13.

42 Alain Badiou, "Ontologie et mathématiques : Théorie des Ensembles, théorie des Catégories, et théorie des Infinis, dans L'Être et l'événement, Logiques des mondes et L'immanence des vérités", pp. 15-34.

43 Alain Badiou, "Five Points - Final Speech", Youtube, 2018, https://www.youtube.com/ watch?v=iWws287P1OU. 
such thinkers as Lucretius and Democritus in it. But on the other hand, therein he also admitted that he "forced" something onto mathematics, since ZFC is not a theory of the multiple in any available ontological sense of "multiple."

Despite these admissions, it is my view that Badiou falls short of providing a satisfactory alternative narrative with regard to the exact role of mathematics for his systematic philosophical works. In any case, he seems far from recasting his interpretations as extended examples of analogical reasoning, which is my present view. I have already discussed why the alleged connection between the ontologies of Lucretius and Democritus, on the one hand, and modern set theory, on the other, is a spurious one. And Badiou admits that the connection is rather loose. However, he continues to describe the study of ZFC and its extensions as the study of "all possible forms of the multiple," where the concept of multiple is taken to have a direct ontological resonance. Furthermore, he emphasises that his ontological decision can be appreciated "at the level of the consequences," e.g. upon consideration of his interpretation of Gödel's and Cohen's theorems. But if the basis of the analogical argument is spurious, how can we accept or appreciate the consequences? The whole project revolves around using mathematical proofs in support of anthropological propositions. It seems that Badiou's auto-criticism falls short of admitting the creative and analogical nature of his interpretations.

\section{References}

Badiou, Alain, Being and Event, trans. Oliver Feltham, Continuum Books, London and New York 2005

- "Five Points - Final Speech”, Prague Axiomatic Circle, Prague 2018 [Youtube], available at: https://www.youtube.com/watch?v=iWws287P1OU

- Theory of the Subject, trans. Bruno Bosteels, Continuum Books, London and New York 2009

- "The Question of Being Today", in Briefings on Existence: A Short Treatise on Transitory Ontology, trans. Norman Madarasz, SUNY Press, New York 2006

Baki, Burhanuddin, Badiou's Being and Event and the Mathematics of Set Theory, Bloomsbury Academic, London and New York 2015

Bartlett, A. J. and Justin Clemens (eds.), Alain Badiou: Key Concepts, Acumen Publishing Limited, Durham 2010

Corcoran, Steven (ed.), The Badiou Dictionary, Edinburgh University Press, Edinburgh 2015 
Cohen, Paul, Set Theory and the Continuum Hypothesis, Dover Publications, Mineola 2008

- “The Discovery of Forcing”, Rocky Mountain Journal of Mathematics 32 (4/2002), pp. 1071-1100

Leibniz, Gottfried Wilhelm and Antoine Arnauld, The Correspondence between Leibniz and Arnauld, trans. Jonathan Bennett, 2017, available at: https://www.earlymoderntexts.com/assets/pdfs/leibniz1686a_1.pdf

George Lakoff and Rafael E. Núñez, Where Mathematics Comes from: How the Embodied Mind Brings Mathematics into Being, Basic Books, New York 2000

Harte, Verity, Plato on Parts and Wholes: The Metaphysics of Structure, Clarendon Press, Oxford 2002

Hegel, Georg Wilhelm Friedrich, The Science of Logic, trans. George di Giovanni, Cambridge University Press, Cambridge 2010

Varzi, Achille, “Mereology,”, Stanford Encyclopedia of Philosophy, Edward N. Zalta (ed.), 2016, available at: https://plato.stanford.edu/archives/win2016/entries/mereology/ 